In "Notes about Landscape, seen and unseen", my proposal is, through my artistical practice, to explore the idea that the experience of the daily scenery occurs in the surroundings, in an accelerated movement of view points, where the non vision points, the unseen, multiply themselves according to our ways of displacement and our routine blindnesses. It's in that dialectics between what we see and what we don't see, what we don't see and what we imagine that constitutes the experience of the daily scenery, where it's not a matter of seeing everything, but a matter of coming closer in order to inhabit.

Keywords: Landscape, seen, unseen. 


\section{Notas sobre paisagem, visão e invisão ${ }^{1}$}

Em "Notas sobre paisagem, visão e invisão", minha intenção é, através da minha prática artística, desenvolver a idéia de que a paisagem cotidiana se revela em meio às coisas, em um movimento acelerado de pontos de vista distintos, ela é passagem, um deslocamento do olhar. Experimentá-la então, seria como ativar um movimento do olhar onde ver e não ver se articulam, onde os pontos de não visão, de um certo estado de cegueira se transformam em invisão, em uma visão interna. E é nesta dialética entre ver e não ver, entre não ver e ver internamente que se constitui o que chamamos de paisagem. Aqui, não se trata de ver tudo, mas sim de se aproximar para habitar, de se situar para olhar no mesmo, no espaço de sempre, a diferença.

Palavras-chave: Paisagem, visão, invisão. 
O que se produz entre o olhar e o espaço cotidiano, urbano ou não, para que este último possa ser percebido como paisagem? Partimos da idéia de que esta se revela em meio às situações rotineiras e banais, em um movimento acelerado de pontos de vista distintos, ela é passagem, um deslocamento do olhar.

Isso significa pensar nas formas de ver, os olhos so o lugar da paisagem ${ }^{2}$. Nesse sentido, podemos pensar na interrogação que Merleau-Ponty ${ }^{3}$ faz à Cézanne acerca da montanha Sainte-Victoire. Ele se pergunta o que exatamente quer o pintor da montanha, o que ele pede à montanha? Pede-lhe desvelar os meios, apenas visveis, pelos quais ela se faz montanha aos nossos olhos. ${ }^{4}$

Experimentar a paisagem no cotidiano seria ativar um movimento do olhar onde ver e não ver se articulariam, onde os pontos de não-visão, de um certo estado de cegueira se transformariam em inviso, em uma visão interna. Não se trata de ver tudo, de ver em panorama, mas sim de se aproximar para habitar, de detalhar para se situar, para olhar no mesmo, no espaço de sempre, a diferença.

Assim, a experiência da paisagem no cotidiano se forja na junção de uma certa maneira de olhar e dos caminhos percorridos. Ela tomaria forma a partir de detalhes corriqueiros que, por serem vistos e (re)vistos continuamente, se tornariam in-visíveis aos nossos olhos. Como então interromper, mesmo que momentaneamente, nossa percepção visual rotineira para que se instale uma percepção inusitada, uma experiência sensível do nosso espaço de todos os dias? Em outras palavras, como através da prática artística, o espaço rotineiro da cidade vai se revelando como uma paisagem singular, como um espaço-em-paisagem?

\section{Habitante-artista-habitante}

Na minha pesquisa plástica minha intenção é sempre articular duas posturas pessoais: a primeira é aquela que denomino a postura da habitante da cidade onde tento compreender como eu percorro os espaços da rotina e da repetição, onde eu me 
interrogo em que momento esse espaço se transforma em um espaço-em-paisagem? A segunda postura é a da artista plástica, que tenta restituir o mais fielmente possível as transformações perceptivas vividas, onde eu me pergunto como apreender e como tornar visível a viso-minha-do visvel ${ }^{5}$ sem trair aquilo que vivi?

Dessa articulação emergem três questões:

- Primeiramente, o que vejo?

- Em seguida, como vejo?

- E por fim, o que vejo quando não vejo?

Na minha prática teórico-artística tento explorar essas questões a partir de dois eixos principais de reflexão: a paisagem e o movimento do olhar, este último englobando ver e não-ver ou in-ver.

Logo, pressupondo que o que vejo é uma paisagem, seria interessante tentarmos compreender sucintamente o que é uma paisagem.

\section{Paisagem: ponto de vista, ponto de contato}

Entre tantos autores que discutem a noção de paisagem, poderíamos citar Milton Santos ${ }^{6}$ que, em seu livro $A$ natureza do espao tcnica e tempo, razo e emoo, afirma que, a rigor, a paisagem é apenas uma porção da configuração territorial que é possível ser abarcada pela visão. Nós poderíamos citar também o historiador Alain Corbin ${ }^{7}$ para quem a paisagem é uma certa leitura do espaço. A essas duas visões soma-se a contribuição do geógrafo Augustin Berque ${ }^{8}$ que nos lembra que a paisagem articula o lado objetivo do mundo, isto é, ela se reporta a objetos concretos os quais existem realmente ao redor de todos nós (pedras, montanha...) e o lado subjetivo, singular e íntimo de cada observador.

Nesse sentido, perceber ou reconhecer a paisagem no cotidiano é compreendê-la como uma espécie de aparição, como algo que inesperadamente surge diante de nossos olhos, uma espécie de epifania imprevisível. Seria aquele momento onde os prédios deixariam de ser apenas prédios, continuando a ser os mesmos prédios. É o instante onde conseguimos ver a poe- 
sia das formas, onde o muro se transforma em nuvem ${ }^{9}$.

A paisagem seria então uma maneira singular de ver no mesmo a diferença, seria o momento onde nos aproximamos do espaço e somos enlaçados, atravessados por ele. Ela é ponto de vista, ponto de contato. Essa experiência pode ser pensada como uma fissura, como um hiato que rompe com o tempo da rotina e instala o tempo de um certo ponto de vista, o tempo de uma certa vista. É como se a cada experiência da paisagem, o espaço cotidiano repentinamente ganhasse relevo e se elevasse aos nossos olhos.

\section{Uma prática do banal}

Nada mais comum para os habitantes da cidade que subir ou descer uma rua, olhar a paisagem pelas janelas do carro, do ônibus ou do metrô. Entretanto, é justamente nesta absoluta banalidade que poderiam residir os instantes de paisagem. $O$ que eu evoco na minha prática artística são experiências perceptivas que, se apresentadas de maneira poética, ganham novos sentidos, nos fazem ver, rever, ver mais uma vez, uma vez ainda, aquilo que já havíamos visto tantas vezes.

Uma tautologia poética onde, pela constatação, a evidência nos é mostrada, onde um detalhe, um detalhe qualquer, um quase-nada, um no-sei-o-que teria a capacidade de nos interpelar e orientar nossa percepção espacial. Seria, assim, suscitar o desejo de ver, despertar nossa visão adormecida, colocá-la em

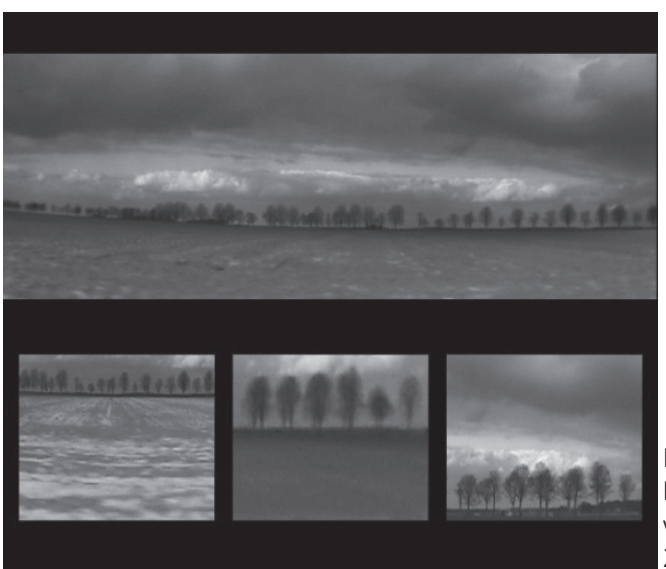

Imagem 1 - Karina

Dias, Passager II, vídeo-projeção, 2006. 
movimento para o olhar o corriqueiro, o habitual, o banal.

Assim, o detalhe é entendido como um micro-evento que nos faz ver melhor, ver do interior, o conjunto que se apresenta diante dos nossos olhos. Ele é aquilo que inquieta nossa maneira de ver, é resistência a uma certa ordem cotidiana, é relevo, é fissura.

Nessa pratica do banal, o espaço cotidiano se transforma em espaço do viajante. Em outras palavras, esse primeiro espaço domesticado, controlado onde tudo parece ocupar um lugar previsível e perene se transforma pela nossa capacidade de olhar, de ver e (re)ver, em um espaço estranho, estrangeiro, irreconhecível temporariamente. É o olhar do viajante que vê o novo no familiar, o caótico na ordem, incluindo o imprevisível no previsível, o imprevisto no previsto. Seria como fixar a atenção para além dos contornos já experimentados, entrevendo na evidência a possibilidade de reestruturar o espaço da rotina e da repetição.

Finalmente não seria assim a experiência da paisagem, uma experiência sensível do espaço? Não seria ela, o vislumbre de perspectivas singulares que nos fazem perceber, pressentir uma estranheza efêmera? Um certo se sentir ailleurs, se sentir longe, em outro lugar, estando no mesmo lugar? Aqui viajar não é se deslocar no espaço, é se deslocar no tempo. A viagem aqui é uma experiência temporal, é um ato de ruptura que instala uma fenda onde se alojaria nossa experiência sensível do espaço... é se dar conta que temos o horizonte no olhar.

Logo, como manter esse olhar alerta? Como desenraizá-lo quando estamos tão enraizados nos espaços da rotina? Poderíamos nos lembrar do personagem Palomar de Ítalo Calvino ${ }^{10}$ cuja principal atividade era observar as coisas. O personagem nos narra como ele observa uma onda do mar e como ele a distingue das demais, ou então como ele observa o reflexo do sol tão perceptível e tão fugidio quando nos aproximamos, Palomar, de toda maneira, no se desencorajava: ele acreditava que a cada instante ele conseguia ver de seu ponto de observao, mas finalmente surgia sempre algo que escapava, que ele no havia se dado conta $[\ldots]^{11}$.

Minha prática artística se localizaria então nesse projeto do 
personagem Palomar, nessa intenção de se situar continuamente no limiar da visibilidade, entre aquilo que vemos e aquilo que escapa ao nosso olhar, entre o visto e o não-visto, num movimento que inclui ver e não ver, onde ver seria como olhar pela primeira vez.

Isto nos conduz a minha segunda questão, como eu vejo?

\section{Eu vejo, eu olho, eu vi}

Poderíamos responder a essa questão como vejo? nos aproximando do movimento do olhar, numa diferenciação de três instâncias: o ver, o olhar ${ }^{12}$ e o visto. Sucintamente, o ver seria ligado a nossa capacidade fisiológica, basta abrir os olhos para vermos. Como nos assinala Sérgio Cardoso ${ }^{13}$, ele seria um deslizamento horizontal ininterrupto no espaço que nos daria a sensação de totalidade, de homogeneidade. Poderíamos acrescentar que o ver é um movimento que nos lançaria numa visão panorâmica.

Por outro lado, o olhar seria um movimento interno do sujeito que interroga, pensa e se inquieta com aquilo que se apresenta diante dos olhos. O olhar é um ato intencional de dirigir os olhos para discernir e é incitado por um apelo sensorial (uma luz, um barulho...), por uma mudança no campo do ver que suscita que a "coisa" seja considerada. Citando novamente Cardoso, o olhar é vertical, ele rompe com a linearidade do campo do ver, fissurando assim a sensação ilusória de totalidade. Assim, podemos sugerir que o olhar é o olho vivo, é o olho alerta.

A terceira e última instância é o visto, àquela que teria a capacidade de preservar o que foi olhado, é como a conclusão do processo seletivo do olhar. Essa instância isola e instala o visível, armazena aquilo que foi garimpado pelo ato de olhar. Poderíamos pensar o visto como a memória de um visível triado, filtrado e eleito que adviria de um tipo de duelo entre aquilo que conseguimos ou não ver. O visto seria a pausa, o instante capturado onde estaríamos numa memória que é o presente que dura.

Se o ver nos dá a sensação de abarcar de uma só vez, o ato 
de olhar trabalha na descontinuidade, na fragmentação, no detalhe. Se o ver é superfície, o olhar é profundidade, se o ver é uma cobertura rápida do espaço, o olhar é atravessamento, ele tem um objetivo, um alvo, ele é aproximação.

Portanto, estabelecendo uma seleção, o movimento do olhar nos posiciona sempre entre aquilo que desejamos ver, aquilo que realmente vemos e aquilo que ainda não vemos. Nesse sentido, a inquietação que se instala é se aquilo que ficou fora da nossa focalização, do nosso alvo, mas que certamente estava no campo da nossa visão, pode ser considerado invisível aos nossos olhos?

Como designar aquilo que não vimos, mas que estava lá, em algum lugar, informe, indefinido, "na sombra", à espera do nosso olhar?

Chegamos à nossa terceira questão: O que vejo quando não vejo?

\section{Invisão}

Vamos tentar responder essa questão compreendendo o visível pela inviso. Uma inviso que, se nos detivermos nas duas acepções do prefixo IN - negação e inclusão - pode ser explorada ora como uma negação temporária da visão, isto é uma cegueira provisória, ora como visão interna, como a imensidão íntima ${ }^{14}$ singular a cada observador.

Assim, poderíamos afirmar que em tudo que vemos há um não-visto ${ }^{15}$ ou um in-visto que pulsa e, mesmo que ele se encontre na sombra, não é a sombra do visível. Ele é, pois, uma instância bem presente, talvez já percebida pelo nosso olhar, mas ainda não vista. O não-visto pode a todo o momento surgir no visível, ele está lá, em qualquer lugar, talvez já visto por alguém, na iminência de aparecer, de ser singularizado, delimitado, distinguido.

O não-visto é informe e está sempre próximo de um ponto de ebulição possível. Ele não é o negativo do visível, não é sua semelhança, mas ele é alteridade. Ele está no limiar da nossa visão e estaria sempre em vias de..., em vias de se tornar visto. Poderíamos dizer que tudo aquilo que foi visto, o foi porque o 
olhar conseguiu enquadrar, delimitar, envolver.

Poderíamos, então, nos interrogar se no quotidiano não estaríamos num eterno estado de inviso, isto é de não-visão, de cegueira voluntária e que teríamos apenas alguns lampejos de visão clara e distinta?

Nós sabemos que a faculdade da visão organiza o mundo e que a cegueira desenvolve outros sentidos. Longe de fazer aqui uma apologia da cegueira, na inviso nós entramos num mundo embaçado, indistinto, indiferenciado. O que nos interessa nesse estado de cegueira transitória é a possibilidade de se ultrapassar os limites impostos pelo mundo da visão. É abrir espaço, dar lugar a percepções de outra ordem, a novas interpretações que, como nos lembra Eugen Bavcar ${ }^{16}$, sob o peso demasiado do visual ${ }^{17}$ não conseguem traçar um caminho.

Na minha prática artística o exercício da cegueira se dá, por exemplo, quando privo o espectador de uma parte da vista apresentada. Nos meus trabalhos ver e não ver são inelutavelmente ligados e o espectador entra e sai permanentemente de uma forma de cegueira. Minha intenção é metamorfosear esse estado de cegueira cotidiana em desejo de ver, de ver paisa-

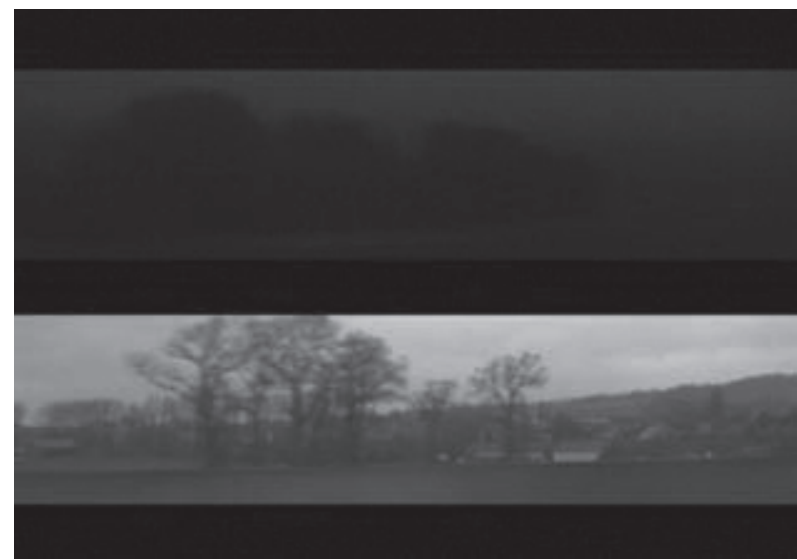

gem

Nesse sentido, ver as paisagens do cotidiano significa sair desse estado cego, desse excesso de visível que acaba por nos cegar, para explorar as zonas sombreadas da visão. É tentar 
ocupar este terreno pouco luminoso, habitá-lo com desenvoltura, situando o espectador não no centro de um nada qualquer, mas no centro de um mundo que sai da sua reserva. Diferentemente de um cego de nascença, nosso olhador-cego pode a qualquer momento "liberar" os olhos e tudo reordenar.

Ir de uma margem a outra, entre o visto e o não-visto, entre visão e inviso, tendo a memória como aliada parece ser a situ-ao imposta aos espectadores dos meus trabalhos. Seria como nos diz Hélène Cixous ${ }^{18}$, atravessar a nado o estreito que separa o continente cego do continente da visão. Se nós evocarmos a experiência da visão como a experiência da forma e do limite, o que interrogo com a minha prática artística é até onde vai esse limite, até onde nossos olhos vêem, qual é o limite do nosso olhar?

\section{Noite noturna ${ }^{19}$}

A noite é um mundo informe na forma, é a presença de um mundo que se tornou outro continuando a ser o mesmo. Experimentá-la então nos engaja numa certa modulação do olhar, pois, na noite tudo se altera: nossa visão se reduz, nossos marcos espaciais se transformam. Ficamos submersos pela escuridão, no entanto não ficamos completamente cegos.

Minha pesquisa plástica se concentra naquilo que a noite nos deixa ver de sua paisagem, isto é, até onde conseguimos ver uma paisagem noturna? Aqui a noite é compreendida como um dos territórios da inviso.

De um lado, temos o dia e o prestígio que Ihe é conferido através da luz que nos permite tudo ver e cultuar as idéias claras e distintas. Por outro lado, temos a noite, esse momento em que experimentamos a desaparição dos contornos, o apagamento dos limites. Se invertermos mais uma vez nosso raciocínio, a noite poderia se transformar em um momento privilegiado, onde o olhar liberado do compromisso da luz, libera também as formas de suas identidades singulares.

Para Geneviève Clancy ${ }^{20}$, a noite é um estado de espessura da luz. Aqui, a noite noturna não é a noite do sono e dos sonhos, mas sim a do despertar de nossos sentidos, de nossas 
percepções. Seria como abrir os olhos na sombra, colocando em movimento o olhar-sombra. Noite sem limites que, segundo Didi-Huberman ${ }^{21}$, quando a experimentamos, se transforma no lugar por excelência, no meio do qual estamos absolutamente.

Nesse sentido, cabe a nós observadores, olhadores, do dia metamorfoseados em olhadores da noite, a restabelecer a ordem das nossas percepções para dar forma às paisagens noturnas. Minha intenção com meus trabalhos é instalar o espectador no meio dessa noite, materializando sucessivamente os instantes de transição, aqueles em que conseguimos ver e aqueles em que aparentemente não vemos mais nada. Ver o pretume da noite não significa nada ver, ao contrário, significa se dar conta do frágil equilíbrio que sustenta nossa percepção de uma paisagem noturna. Paisagem essa que se revela nas nuanças da escuridão da noite. Poderíamos dizer que a noite noturna nos conduz do visível ao imaginável, de um visível compartilhado a um visível não-compartilhado, nossa invisão. Experimentar a noite noturna seria, então, responder a um desejo íntimo, intenso de não se deixar cegar.

\section{Conclusão}

Assim, perceber uma paisagem é ressentir suas faces escondidas, é conjugar o que vejo com o que não vejo, o que escuto com o que não escuto dando sentido ao que olho. É incluir a inviso na visão, o in-visível no visível, não como contrários, mas como desdobramentos possíveis.

Na minha prática-teórica-artística eu me interrogo sobre os limites da imagem face aos limites da nossa percepção visual quando as condições normais de visibilidade se tornam deficientes e que então somos conduzidos a ver de outra forma. Situações onde ver seria se aproximar de um visível que nem sempre é a definição do claro e do distinto, mas de um visível que é a descrição exata do embaçado, do transitório, do indistinto. Como na noite noturna, é preciso modular o olhar, não para retirar o véu que encobre a paisagem, mas para ativar um olhar-sombra, para enxergar a noite tal como ela é, escura, indeterminada, imprevisível. 
Minha intenção é incitar o espectador a tomar posse do seu olhar, a assumir seu lugar de habitante/ olhador/habitante que para ver, para ver o dia, deve dirigir seus olhos para a noite, para a névoa, para as zonas sombreadas da visão, é olhar noturnamente. O que meus trabalhos questionam é como conceber uma paisagem quando o olhar chega ao seu limite e que, então, somos convidados a explorar um continente cego?

A partir dessa ausência, dessa falta, adentramos em zonas enevoadas e imprevisíveis, entramos nas dobras do dia e da noite, da visão e da inviso. Se o nosso mais íntimo desejo é nunca deixar de ver, ver paisagem na minha prática artística seria ocupar a outra margem do rio, seria ajanelar o espaço da rotina para olhar, olhar no cotidiano lá onde aparentemente não haveria nada para se ver.

\section{Notas}

1. As questões aqui abordadas fazem parte da minha tese de doutorado intitulada Le paysage: entre Le vu et l'invu, pour une pratique paysagère dans le quotidien. Tese em Artes Plásticas defendida em setembro de 2007 na Université Paris I - Panthéon Sorbonne.

2. Ibidem.

3. MERLEAU-PONTY, Maurice O Olho e o Espírito. Os Pensadores, São Paulo: Abril, 1980.

4. Ibid., p.281.

5. Em francês la vision mienne in MERLEAU-PONTY, Maurice. Le visible et l'invisible. Paris : Gallimard, 2005, p.19.

6. SANTOS, Milton. A natureza do espaço - técnica e tempo, razão e emoção. São Paulo: HUCITEC, 1999.

7. CORBIN, Alain. L'homme dans le paysage. Paris : Les éditions Textuel, 2001.

8. BERQUE, Augustin (org). Cinq propositions pour une théorie du paysage. Seyssel : Editions Champ Vallon, 1994.

9. Aqui faço referência a Leonardo da Vinci (1452-1519) que ao convidar seus alunos a olhar uma mancha no muro aconselha: "Se olhas para um muro coberto de manchas, ou feito de pedras diferentes[...]verás paisagens variadas, montanhas, rios, rochas, árvores planícies [...] como num som de sino onde cada badalada evoca o nome ou o vocábulo que tu imaginas [...] in BRAMLY, Serge, Biographie de Léonard de Vinci, Carnet II, Paris, Éditions Jean-Claude Lattés, 1995, p. 247.

10. CALVINO, ITALO. Palomar. Turin: Éditeur Guilio Einaudi, 1983. Palomar traduzido do italiano para o francês por Jean-Paul Manganaro. Paris: Éditions Du Seuil, 2003.

11. Ibid,p.14.

12. Remeto o leitor ao texto de Sérgio Cardoso intitulado O olhar viajante (do etnólogo) in NOVAES, Adauto (org) O olhar. São Paulo; Companhia das Letras, 1999.

13. Ibidem.

14. BACHELARD, Gaston. Poética do espaço.Tradução Antônio de Pádua Danesi. São 
Paulo: Martins Fontes, 1998.

15. Tradução aproximativa e provisória do termo em francês invu. Ver minha tese de doutorado intitulada Le paysage: entre Le vu et l'invu, pour une pratique paysagère dans le quotidien. Tese em Artes Plásticas defendida em setembro de 2007 na Université Paris I - Panthéon Sorbonne.

16. BAVCAR, Eugen. Le voyeur absolu. Paris: Seuil, 1992, p.16.

17. O fotógrafo cego Eugen Bvcar faz uma distinção entre o visual e o visível. Para ele, o visual é aquilo que os olhos vêem e o visível aquilo que o espírito vê.

18.CIXOUS, Hélène, DERRIDA, Jacques. Voiles. Paris: Editions Galilée, 1998, p.19.

19. Além da noite, meus trabalhos exploram também a neblina, a bruma e o silêncio. Da mesma maneira que desenvolvo a noção de invisão como uma outra vertente da visão, evoco o inaudível como uma outra vertente da audição.

20. CLANCY, Geneviève. Les cahiers de La nuit. Paris : L'Harmatan, 2004.

21. DIDI-HUBERMAN, Georges. Ce que nous voyons, ce qui nous regarde. Paris : Les éditions de Minuit, 1992, p.71. 


\section{KARINA DIAS}

Doutora em Artes pela Université Paris I - Panthéon Sorbonne, Mestre em Poéticas Contemporâneas pela Universidade de Brasília, Graduada em Licenciatura- Artes plásticas pela Universidade de Brasília. Trabalha com vídeo e intervenção urbana, expondo no Brasil e no exterior. Atua também como professora universitária.Email: bsbkk@ig.com.br 